\title{
The Relationship between Agricultural Development and Economic Growth: The Case of Turkey (1988-2018)
}

\section{Meryem Hakses}

Selcuk University

\begin{abstract}
Agriculture, industry and service sectors take place in the market mechanism. The development of national economies is directly linked to the improvements in these sectors. Turkey is developing various policies to achieve the potential of the agricultural sector. In this context, recent land consolidation, increasing the share of machinery production in agriculture and the initiatives to benefit from the experiences of the European Union can be counted.

The aim of this study was to examine the causal relationship between Turkey specially in agricultural development and economic growth. Annual data on the 30-year period (1988-2018) covering 15 years before and after 2003, when one of the most important reforms were made within the framework of the adaptation period to the agricultural policies of the European Union, were discussed. In this context, Toda - Yamamoto (1995) procedure will be used to investigate the long - term causality relationship between agricultural development and gross domestic product.
\end{abstract}

Keywords: agricultural development; causality; economic growth. 